\title{
Osteomyelitis of the pubis in a young athlete revealed by severe abdominal pain
}

\author{
Lamiae Chater ${ }^{*}$, Karima Atarraf, Moulay Abderrahmane Afifi
}

Department of Pediatric Surgery, CHU Hassan II, Fez, Morocco

Email: ${ }^{*}$ chaterlamia@yahoo.fr

Received 31 July 2013; revised 29 August 2013; accepted 7 September 2013

Copyright (c) 2013 Lamiae Chater et al. This is an open access article distributed under the Creative Commons Attribution License, which permits unrestricted use, distribution, and reproduction in any medium, provided the original work is properly cited.

\begin{abstract}
Acute osteomyelitis is a common condition in children. Only early diagnosis prevents complications. The location at the pubic bones is very rare, even exceptional at the pubis symphis. We report a case of osteomyelitis of the pubis in a young athlete of 14 years old whose symptoms were discussing an acute abdomen, to illustrate the unusual clinical presentation, so as not to miss the diagnosis and avoid unnecessary laparotomy.
\end{abstract}

Keywords: Osteomyelitis; Pubis; Childhood; Athlete; Acute Abdominal Pain

\section{INTRODUCTION}

Acute hematogenous osteomyelitis is a bone disease caused by a germ usually the staphyloccocus aureus. Its headquarters is fertile metaphysis of long bones near the knee and far from the elbow. Diagnosis is clinical and must be as early as possible to initiate treatment quickly, otherwise the risk of fatal sepsis and especially the evolution to the chronicity is significant [1].

Osteomyelitis of pubis represents less than $1 \%$ of locations. The pathogenesis of this entity is explained by the location of a secondary bacteremia on undisturbed bone.

We report a case of pubic osteomyelitis in a young boy practicing a sporting activity revealed by acute abdominal pain to illustrate the somewhat unusual presentation.

\section{CASE PRESENTATION}

A young judoka aged 14 years was admitted to our hospital for severe abdominal pain. The symptoms started it a week ago, when a history of severe right lower quad-

"Corresponding author. rant abdominal pain with a fever was developed. There was a history of local trauma in the pelvic area 20 days before. The boy reported worsening abdominal and suprapubic pain radiating to both groins and preventing ambulation. He was vomited nonbilious. Physical examination has objectified a fever to $39^{\circ} \mathrm{C}$, and abdominal examination showed right lower quadrant tenderness, but remains soft. The leukocyte count was $11,400 \mathrm{cells} / \mathrm{ml}$. The erythrocyte sedimentation rate was $97 \mathrm{~mm} / \mathrm{h}$ and the C-reactive protein (CRP) level was $25 \mathrm{mg} / \mathrm{l}$.

A pelvic radiography (Figure 1) showed osteolysis of the upper inner angle of the right pubis without periosteal reaction. Ultrasonography showed a hypoechoic collection of $10 \mathrm{~mm}$ behind the rectus abdominis muscle. A computed tomography scan of the abdomen and pelvis revealed a hypodensity collection around the pubic symphysis (Figure 2) with an osteolytic appearance of the pubis (Figures 3 and $\mathbf{4}$ ). These findings were consistent with osteomyelitis of the pubis with suppuration.

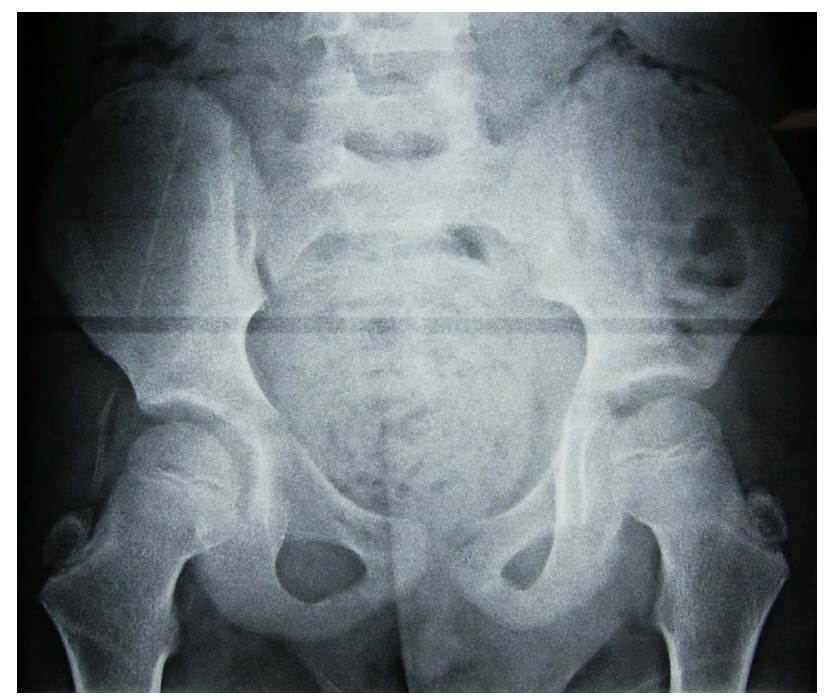

Figure 1. Pelvic radiography showed slight deformity with irregularity of the right side of the pubic symphis. 


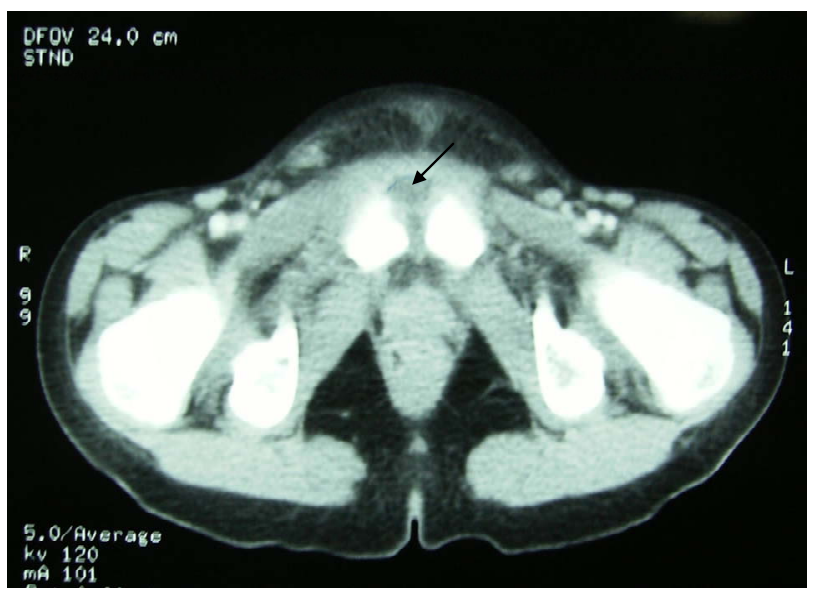

Figure 2. Computed tomography scan of the abdomen and pelvis revealed a hypodense collection arround the pubic symphis.

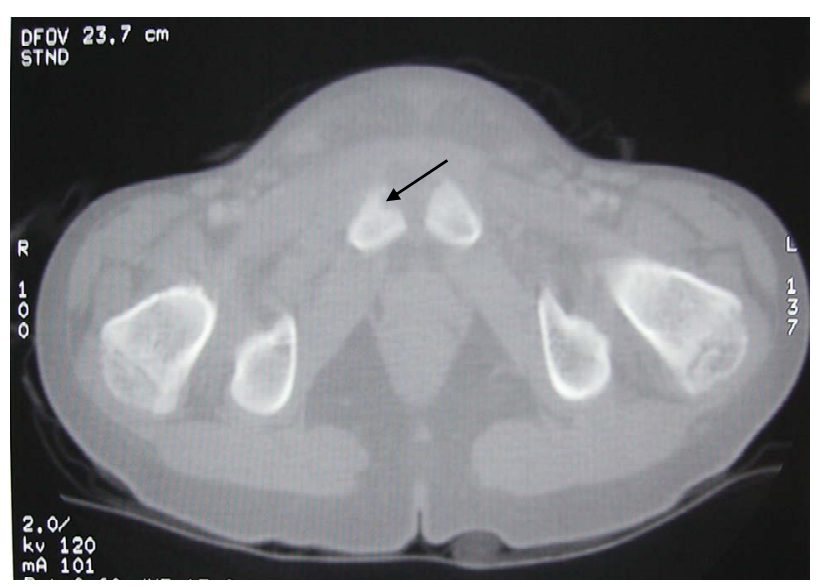

Figure 3. Computed tomography scan of the pelvis: an osteolytic appearance of pubic symphis.

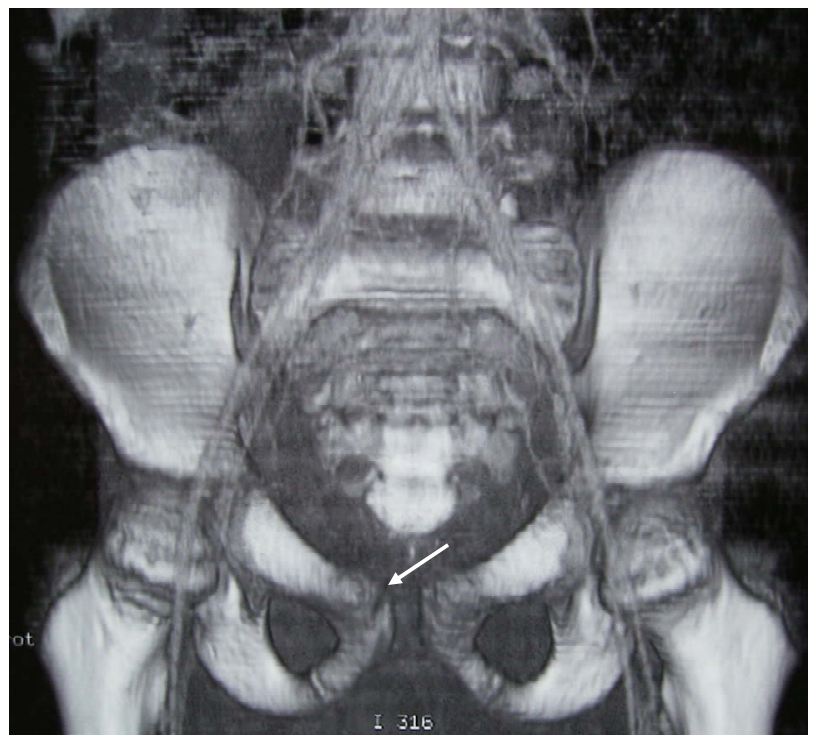

Figure 4. Computed tomography scan of the pelvis in 3D showed an osteolytic appearance of pubic.
The symphis pubis was explored through a Pfannenstiel-type incision. 3 cc of the pus was encountered and the bone appeared soft and distinctly abnormal. Bacteriological study showed gram positive cocci, and culture yielded a light growth of Staphylococcus aureus. The staphylococcus was sensitive to flucloxacillin, so this drug was given intravenously for 10 days, then orally. Histopathological study of fragments of bone tissue from the lesion was consistent with the diagnosis of the osteomyelitis of the pubis.

The boy remained without fever and the local pain disappeared. His gait gradually returned to normal. His white blood cell count normalized and his CRP level was descending.

\section{DISCUSSION}

Osteomyelitis of the pelvic bones accounts for between $3 \%$ and $8 \%$ of cases of osteomyelitis in childhood [2]. Localization in the bones around the pubic symphysis is very rare. And the involvement of the pubic symphysis is exceptional and often undiagnosed condition causing abdominal pain.

Osteomyelitis of the pubis in athlete is exceptional with only nineteen cases reported in the literature. The age of onset varies between ten and 28 years [3,4].

The pathophysiology remains unclear. In athletes, some authors have discussed the role of pre-existing damage of the pubis by the microtrauma which would promote bacterial infection during a transitional bacteremia [3-5].

A detailed medical history is necessary to help the doctor to make the diagnosis. Indeed, osteomyelitis of the athlete usually occurs in the aftermath of a sport. Usually there is a history of fever at the onset of the illness [6]. Thorough examination of the groin, abdomen, hips, spine and lower limbs is essential [7].

Sometimes, clinical examination can objectify sensitivity or defense of the right iliac fossa or next to the pubic symphysis. These symptoms can be easily confused with acute appendicitis [1] especially if they are associated with vomiting and febrile syndrome as is the case of our patient, hence the importance of a good interview and a thorough clinical examination to avoid abusive laparotomy.

The diagnosis of osteomyelitis is essentially clinical. Laboratory data are not required for the diagnosis. There may be an increased leukocyte cells count and an elevated sedimentation rate, similar to data found with acute abdominal pain.

The radiograph of the pelvis centered on the pubis often shows irregular cortical and osteolysis. Later appears bone sclerosis $[5,8,9]$. These radiographic signs appear a few weeks after the onset of clinical symptoms $[4,5,8]$. 
Ultrasound can explore early and quite different facets of the pelvic bone in search of a subperiosteal abscess. Bone scintigraphy can also provide early signs showing a hypersignal in pubic symphysis [4].

MRI appears the most effective for the diagnosis of osteomyelitis of the pubis [8]. It shows signs of edema and inflammation resulting in abnormal signal of the bone and the symphysis, or muscles. This is a crucial consideration in assessing the presence and extent of pubic infection. The typical appearance is localized with decreased signal on T1-weighted images and signal enhancement in T2-weighted image area.

Staphylococcus aureus is the organism most commonly involved. Its isolation is made by blood cultures and puncture-aspiration, if not by open surgery $[3,8,10]$.

The main differential diagnosis is with osteitis pubis in athletes. Originally described by Beer in 1924, osteitis pubis is an inflammatory process and non-infectious [8,9,11-13]. The sports activity is a predisposing factor $[4,6-9,12,14]$. It usually occurs after surgery of the urogenital tract. Osteitis of the athlete could increase the risk of osteomyelitis [12].

The treatment of pubic osteomyelitis requires appropriate antibiotic. Initially antibiotics are given intravenously for two weeks, followed by oral antibiotics for at least six weeks. In rare cases, surgery is necessary to drain a retropubic abscess, curettage of the lesion or removal of bone sequestration $[3,10]$.

\section{CONCLUSIONS}

A good knowledge of the disease should allow a diagnosis before the stage of subperiosteal abscesses and early treatment, which makes the exceptional surgical indications.

These conditions are often overlooked or masked by abdominal pain, which may lead to unnecessary tests and procedures.

\section{REFERENCES}

[1] Diane, V., Pham, M.D. and Kendall, G.S. (2007) Presentation of osteitis and osteomyelitis pubis as acute abdominal pain. TPJ Spring, 11, 2.

[2] Morrey, B.F. and Peterson, M.A. (1975) Hematogenous pyogenic osteomyelitis in children. Orthopedic Clinics of North America, 6, 935-951.

[3] Essadam, H. and Hammou, A. (1998) Ostéomyélites radio diagnostic-neuroradiologie-appareil locomoteur. Elsevier, Paris, 1-18.

[4] King, R.J. and Laugharne, D. (2003) Primary obturator pyomyosis: A diagnostic challenge. Journal of Bone \& Joint Surgery (British Volume), 85B, 895-898.

[5] Knoeller, S.M., Hul, M. and Herget, G.W. (2006) Osteitis or osteomyelitis of the pubis a diagnostic and therapeutic challenge. Report of 9 cases and review of the literature. Acta Orthopaedica Belgica, 72, 541-548.

[6] Simms, R.G., Brown, B.S., Hyndman, J.C. and Goldbloom, R.B. (1981) Osteomyelitis of the pubis in childhood. CMA Journal, 15, 124.

[7] Morelli, V. and Espinoza, L. (2005) Groin injuries and groin pain in athletes: Part 2. Primary Care: Clinics in Office Practice, 32, 185-200.

http://dx.doi.org/10.1016/j.pop.2004.11.012

[8] Magarian, G.J. and Reuler, J.B. (1985) Septic arthritis and osteomylitis of the symphisis pubis (osteitis pubis) frum intravenous drug use. Western Journal of Medicine, 142, 691-694.

[9] Malakzadah Shirvani, P., Willkholm, E. and Assaf, A. (2007) Osteitis pubis simulating a soft tissue lesion. Canadian Journal of Surgery, 50, 17-18.

[10] Mc Murtry, C.T. and Avioli, L.V. (1986) Osteitis pubis in an athlete. Calcified Tissue International, 38, 76-77 [crossref]. http://dx.doi.org/10.1007/BF02556833

[11] Pham, D.V. and Scott, K.G. (2007) Presentation of osteitis and osteomyelitis pubis as acute abdominal pain. Spring, 12, 65-68 [cross-ref].

[12] Sève, P., Boibieux, A., Pariset, C., Clouet, P.L., Bouhour, D., Tigaud, S., et al. (2001) Les ostéomyélites du pubis de l'athlète. La Revue de Médecine Interne, 22, 576-581. http://dx.doi.org/10.1016/S0248-8663(01)00390-3

[13] Simms, G.R., Brwn, B.S.T.J., Hyndman, J.C. and Goldbloom, R.B. (1981) Osteomyelitis of the pubis in childhood. Canadian Medical Association Journal, 124, 10281030.

[14] O’Connell, M.J., Powell, T., McCaffrey, N.M., O’Connell, D. and Eustace, S.J. (2002) Symphyseal cleft injection in the diagnosis and treatment of osteitis pubis in athletes. American Journal of Roentgenology, 179, 9559. http://dx.doi.org/10.2214/ajr.179.4.1790955 